\title{
Boundary Objects as Facilitators of Knowledge Transfer in Project Based Organisations
}

\author{
Rosanna Butters and Meri Duryan \\ Transport for London, UK \\ University College London, UK \\ Rosanna.butters.16@ucl.ac.uk \\ M.duryan@ucl.ac.uk \\ DOI: 10.34190/KM.19.016
}

Abstract: Boundary objects are tools used to transfer knowledge across organisational and functional divides. Where boundaries can create challenges for organisational learning and knowledge management, boundary objects can be an effective tool for overcoming them through translation and communication. Much of the project work in today's large infrastructure organisations is carried out by cross-functional teams under pressure to deliver project objectives on time and within budget and it is crucial for staff to access meaningful information and knowledge from experts in the organisations involved in projects and from other areas of the business. Understanding the features that make boundary objects effective can improve organisational learning and better inform decision-making, eventually improving organisational performance. This paper assesses whether the features of boundary objects found to be effective in biological and manufacturing environments are valid in project-based industries, particularly construction. The findings suggest that, by maximising the efficacy of boundary objects, large construction organisations can address the knowledge-sharing issues literature has identified as arising from the complex and temporary nature of construction projects. This article contributes to theory by identifying three new features of boundary objects, in addition to those listed by Leigh Star, that are used effectively in the organisation under scrutiny. The findings also demonstrate that all of the features in Star's theory contribute to knowledge transfer in a project-based environment, although not all are as effective compared to other industries.

Keywords: boundary objects, knowledge sharing, construction projects, organisational learning

\section{Introduction}

Retention and transfer of knowledge, a challenge for all types of organisations, is even more challenging in project-based organisations due to the complexity, uniqueness and temporary nature of project work and high staff turnover caused by factors such as cost and time pressures and job security. Prominent researchers like Argyris and Schön (1978) have focused on how organisations can use the knowledge and experience of their experts to improve through organisational learning (OL), while other authors (e.g. Williams, 2008) have focused on the mechanisms that facilitate the storage and transfer of knowledge as part of knowledge management (KM). The more intuitive tacit aspect of knowledge and learning means these two concepts are closely connected to Actor-Network Theory (ANT) and Wenger's (2010) theory of communities of practice (CoPs) which demonstrates that bridging gaps between groups is critical to $\mathrm{OL}$ and $\mathrm{KM}$. Boundary objects (BOs) have been identified as an effective tool for transferring knowledge between these groups. Face-to-face interaction is crucial for transferring tacit knowledge that resides in people's minds. However, in project-based environments, especially in dispersed programs where there is little or no opportunity for face-to-face communication, BOs can be used to promote the sharing of knowledge in practice between diverse groups (Brown and Duguid, 2001). The most prominent researcher in the field of BOs, Leigh Star (1989), has identified key features of BOs. Her findings defining these features have been confirmed by subsequent works in the field, which echo Star's conclusion that BOs bridge gaps through 'translation' (e.g. Hustad, 2007) and 'processes' (e.g. Luna-Reyes et al., 2018).

The overriding problem for $\mathrm{BO}$ is that $\mathrm{OL}$ needs adequate $\mathrm{KM}$ infrastructure and understanding of what information is important and when to transfer knowledge. This study focuses on whether the BO features identified by Star and others improve BOs' ability to transfer explicit knowledge in construction projects. As most BOs are inanimate objects that transfer knowledge which can be articulated rather than inferred or implied, this study focuses more on explicit knowledge. While Star's theory has been applied in influential studies in the medical, manufacturing and IT sectors, the construction industry remains relatively unexplored. Many of the studies based on Star's theory were conducted in a manufacturing environment, where the more repetitive nature of the work and lower turnover of staff may make it easier to incorporate lessons learned into day-today activities, so applying it in the environment of construction projects indicates potential areas for improving the theory. This study aims to understand whether Star's theory is valid in a project-based context. 
The main question this paper addresses is whether the features of the BOs used in the project-based construction organisation under scrutiny are the same as those identified in Star's works. The paper contributes to practice by identifying which BO features can help organisations manage the information and knowledge they have to better inform decision-making and improve performance. The small sample size of this study and containment to one sector means that conclusions drawn from the findings are limited, but the study can provide a valuable indication as to which areas of the BO field warrant further investigation.

\section{Theoretical framework}

The most common terminology used to describe the movement of knowledge across different organisational boundaries is knowledge transfer (Szulanski, 1996; Argote, 1999). Knowledge transfer across boundaries increases chances of project success by improving productivity, efficiency and motivation, and effective BOs help projects achieve their objectives (Wenger, 2000; Star and Ruhleder, 1996).

\subsection{Knowledge management and organisational learning in a project-based environment}

Research on KM and OL has been shaped by Polanyi's (1967) identification of tacit knowledge, whereby information and experiences are understood through feelings and associations, as opposed to explicit knowledge that can be articulated and codified. The distinction between tacit and explicit knowledge needs to be considered to recognise the situated and interpretive challenges of knowledge transfer across boundaries. The non-human nature of BOs means explicit knowledge is more prevalent in this study, however Polanyi's (1967) view that tacit and explicit knowledge are integrated is adopted when analysing the results.

KM focuses on how knowledge is acquired, stored and communicated. According to Morris and Loch (2006), OL focuses on how organisational culture and structure can promote or inhibit knowledge flow across the organisation to affect performance. Unlike individual learning which occurs in a person's mind, OL is a complex interpersonal process occurring in a social arena (e.g. Lipshitz, Popper and Friedman, 2002).

Learning and knowledge are viewed as two stages of a project knowledge process, with learning part of 'knowledge formation' and knowledge being supported by learning activities (Kotnour, 2000). BOs play a significant role at each of these stages (Morris and Loch, 2006; Szulanski, 2000; Carlile, 2002). The concept of BO (Star and Griesemer, 1989) is currently being considered as a project management tool promoting knowledge transfer between diverse project groups (Yakura, 2002).

$\mathrm{KM}$ and OL are particularly important in projects due to their unique and temporary nature (Williams, 2008). While BOs can be a mechanism for transferring knowledge in organisations, several factors make it challenging to successfully implement them. Cost pressures make it hard to justify investment in OL and KM tools that may have intangible results, particularly in construction organisations where high levels of risk, uncertainty and low margins discourage people from investing the time and resources needed (Smyth, 2006; Eriksson, 2010).

\subsection{Sociology and boundaries}

$\mathrm{KM}$ and $\mathrm{OL}$ emphasise the sociological relationship between knowledge, work practices and social context and groups, as silos and time lapses between lessons can prevent them from being learned. ANT and CoPs help explain how those using a BO determine its effectiveness through users' power (Scoles, 2018), identity (Harrison et al., 2018) and shared understanding (Rosenkranz, Vranešić and Holten, 2014).

ANT's concept of connections between users is central to BO theory but these connections are seen to be between all actors, rather than being determined by managers (Star and Griesemer, 1989). Although there is a difference in emphasis between BO and ANT theory, Scoles (2018) does not see this as a significant point of contention between the two fields. Studies on knowledge transfer through ANT explain that the social structures associated with BOs contribute to their usefulness and meaning (Thompson, 2016; Scoles, 2018; Thomas, Sargent and Hardy, 2008).

CoPs' identity is defined by their knowledge rather than their task and, as CoPs are differentiated from other groups by boundaries, they are useful for examining learning loops and knowledge production (Brown and Duguid, 2011). CoPs' ability to represent formal and "invisible" relations that enable transfer and integration of knowledge can dictate the efficacy of BOs (Hustad, 2007; Kanwal et al., 2018). 


\subsubsection{Brokers}

Wenger (2000, p.233) identifies four types of brokers but only 'boundary spanners', which 'take care of one specific boundary object over time', are relevant to this study. As brokers' gatekeeper-like role of controlling the information input into BOs can promote and facilitate its use (Breengaard, Jørgensen and Duncan, 2018), this study takes brokers' impacts into account when reviewing BO success, but the scope does not cover the efficacy of brokers themselves.

\subsection{Boundary objects}

Star and Griesemer (1989, p.393) define BOs as: 'objects which both inhabit several intersecting social worlds... and satisfy the informational requirements of each of them'. Tools, documentation, models, drawings, charts, software programmes, spreadsheets and events are all examples of BOs.

BOs improve project learning by acting as a means of translation and communication through which learning can be understood. The learning process can be improved by introducing repetition that allows actors to learn their roles (Sajtos, Kleinaltenkamp and Harrison, 2018). Considering that BOs do not have knowledge embedded within them (Gourlay, 2007; Szulanski, 2000), there must be a degree of similarity between the groups using them (Wenger, 2000). Political context, strong interdependencies between groups, a culture of cost-saving or collaboration or management support contribute to the success or failure of BOs (Star, 2010; Azizi, Rowlands and Haass, 2018).

\subsubsection{Characteristics of boundary objects}

Literature on the characteristics of BOs is mainly project-based and draws mainly from Star's works (Star, 1989; Star and Griesemer, 1989). While various studies explore BOs most of them have been conducted in the fields of zoology and medicine. Few studies have been conducted in engineering and even fewer in construction. In the transport planning field, Biermann and Martinus (2016) assessed the effectiveness of BOs against KM benchmarks of salience, credibility and legitimacy (Cash et al., 2003), but as construction, especially in transport organisations, focuses more on engineering rather than transport planning, their work is not considered to be a study in construction in transport.

Key papers on BOs in manufacturing (Henderson, 1991; Koskinen and Mäkinen, 2009; Whyte et al., 2008) emphasise the importance of visual representations, such as computer-aided design and modelling (CAD and CAM). An effective feature not mentioned by Star but identified by studies of boundary-spanning software is homeostasis, an attribute that allows the BO to readjust itself as needed to meet its objectives (Datta and Acar, 2010).

\subsubsection{Attributes of boundary objects}

The central position of Star's works in literature on BOs makes it appropriate to review existing theory and assess whether Star's dominance is preventing authors from questioning and expanding on her findings. Star's features of $\mathrm{BOs}$ were reiterated by later studies in the field and her terminology used to interpret findings (Huvila et al., 2017).

Star's work (1989) identifies three attributes of successful BOs. Subsequent BO literature, particularly in the ANT field (e.g. Scoles, 2018; Thompson, 2016), has reinforced her conclusion. The first feature is interpretative flexibility that allows the concept to be interpreted in different ways by different users. The second feature prescribed by Star is the right dynamic between being ill-structured whilst allowing tailored use of the objects and having a strong enough structure to maintain a common identity while being flexible enough to be moulded for local use. The third attribute is the structure of informatic and work arrangements, a feature that relates to both the interactive way in which BOs are created and maintained, and how it relates to its external infrastructure.

Star and Ruhleder (1996) developed this theory by identifying effective features of boundary infrastructure (Table 1) systems that resolve local and global tension similarly to BOs but on a larger scale and usually more practice-based. While some of the BOs examined here could be classified as boundary infrastructure, this study will not differentiate between them as boundary infrastructure features correspond to those of BOs, although whether boundary infrastructure features are directly applicable to BOs has not yet been explored. 


\section{Rosanna Butters and Meri Duryan}

Table 1: Definitions of boundary infrastructure features (Star and Ruhleder, 1996; Star, 2010).

\begin{tabular}{|c|c|c|}
\hline $\begin{array}{c}\text { Boundary infrastructure features } \\
\text { (1996) }\end{array}$ & Definition & $\begin{array}{c}\text { Related BO } \\
\text { feature (2010) }\end{array}$ \\
\hline Becomes visible upon breakdown & $\begin{array}{c}\text { 'The normally invisible quality of working infrastructure } \\
\text { becomes visible when it breaks' }\end{array}$ & \multirow{2}{*}{$\begin{array}{l}\text { Ill-structured } \\
\text { whilst allowing } \\
\text { tailored use }\end{array}$} \\
\hline Built on an installed base & $\begin{array}{l}\text { 'Wrestles with the "inertia of the installed base" and } \\
\text { inherits strengths and limitations from that base.' }\end{array}$ & \\
\hline Embeddedness & $\begin{array}{l}\text { "Sunk" into, inside of, other structures, social } \\
\text { arrangements and technologies'. }\end{array}$ & \multirow{4}{*}{$\begin{array}{l}\text { Structure of } \\
\text { informatic and } \\
\text { work } \\
\text { arrangements }\end{array}$} \\
\hline Embodiment of standards & $\begin{array}{c}\text { 'Modified by scope and often by conflicting } \\
\text { conventions.' }\end{array}$ & \\
\hline Learned as part of membership & $\begin{array}{c}\text { 'Strangers and outsiders encounter infrastructure as a } \\
\text { target object to be learned about. New participants } \\
\text { acquire a naturalized familiarity with its objects as they } \\
\text { become members.' }\end{array}$ & \\
\hline Links with conventions of practice & $\begin{array}{l}\text { 'Shapes and is shaped by the conventions of a } \\
\text { community of practice.' }\end{array}$ & \\
\hline Reach or scope & $\begin{array}{c}\text { 'Spatial or temporal - infrastructure has reach beyond } \\
\text { a single event or one-site practice.' }\end{array}$ & \multirow{2}{*}{$\begin{array}{l}\text { Interpretative } \\
\text { flexibility }\end{array}$} \\
\hline Transparency & $\begin{array}{l}\text { 'Does not have to be reinvented each time or assembled } \\
\text { for each task, but invisibly supports those tasks.' }\end{array}$ & \\
\hline
\end{tabular}

\section{Methodology}

\subsection{Problem statement}

$\mathrm{KM}$ and $\mathrm{OL}$ are particularly problematic in the construction industry due to the complex, temporary and unique nature of construction projects. Functional silos have their own routines, codification methods and skills that inhibit effective knowledge transfer, and geographical distance and different working routines mean that faceto-face exchange of tacit knowledge is not always possible. The main question in this paper is whether the features of the BOs used in the construction industry are the same as those identified by literature to be effective in other sectors. The second is whether there are any new features not considered in Star's theory but still effective in a construction setting as enablers of OL and KM.

The BOs reviewed in this study were identified by either fitting Star's widely used description of BOs, or representing examples of different types of BOs in accordance with Star's definition. Exploring different types of $\mathrm{BO}$ provides a more complete descriptive case study and the following types identified in the literature were included:

- contract (Koskinen and Mäkinen, 2009)

- $\quad$ CAD (Henderson, 1991)

- Gantt (Yakura, 2002)

- GIS (MacEachren, 2001)

- Excel database (Cacciatori, 2008)

- Briefing (Fuller, Dainty and Thorpe, 2011).

\subsection{Background of the case study}

This case study is focused on a series of projects within a large infrastructure programme in a transport company of 27,500 employees. The programme is an upgrade of existing transport infrastructure and consists of multiple projects involving many contractors. Programme milestones are determined centrally and there is a high degree of dependency among the different projects, disciplines and suppliers.

Driven by the need to cut costs, senior management within the organisation has supported the design of effective BOs, but incidents of unsuccessful BOs in the past have increased scepticism towards them. There is, however, an increasingly urgent need for knowledge retention and transfer due to the high turnover arising from the temporary nature of projects. 


\subsection{Data collection and analysis}

A single case study with multiple units of analysis was used to test Star's theory as it allows similar cases to be evaluated and additional features identified (Yin, 2018). Most BO studies used interviews to collect data and this study used a quali-quantitative method. The qualitative nature of the interview questions made it easier to extract meaning from the results and build a holistic picture (Gummesson, 2000) while the quantitative method in which the key phrases mentioned were assessed allowed for identification of patterns.

The BOs chosen for the analysis are the most commonly used in the programme by different groups, meaning that the participants were familiar enough with them to answer the questions. The interviewees were selected from a variety of disciplines and teams within the organisation. To ensure the validity of the data, the interviews were conducted with 28 members (managers and specialists) of two groups: 14 employees from one project (the internal group) and 14 employees who were not part of that project (the external group) with the following comparison of the results. Content analysis was used to evaluate the results and group responses in Star's categories. All the interviewees' responses were assumed to be equally reliable because according to Star and Griesemer (1989), BOs do not discriminate between the types of users.

The interview questions were based on Star's BO and infrastructure categories, and on the recently identified category of homeostasis, as described in the Theoretical Framework. The respondents were encouraged to name as many beneficial features as they could, to allow them to introduce new ideas, not covered by the academic literature.

\section{Discussion and analysis}

Features in Star's categories of BO were cited by participants, suggesting Star's theory is feasible in a construction context and that infrastructure features are a development of, rather than a change to, the original theory. All but one of the infrastructure features were seen by the majority of the participants as positive, and embodiment of standards was the most effective, with nine negative comments out of 77 (Figure 1). Of the BO categories, structure of informatic and work arrangements and ill-structured were predominantly seen as positive, while interpretative flexibility was perceived as negative (Figure 1), most likely due to the concerns over misinterpretation outlined below.

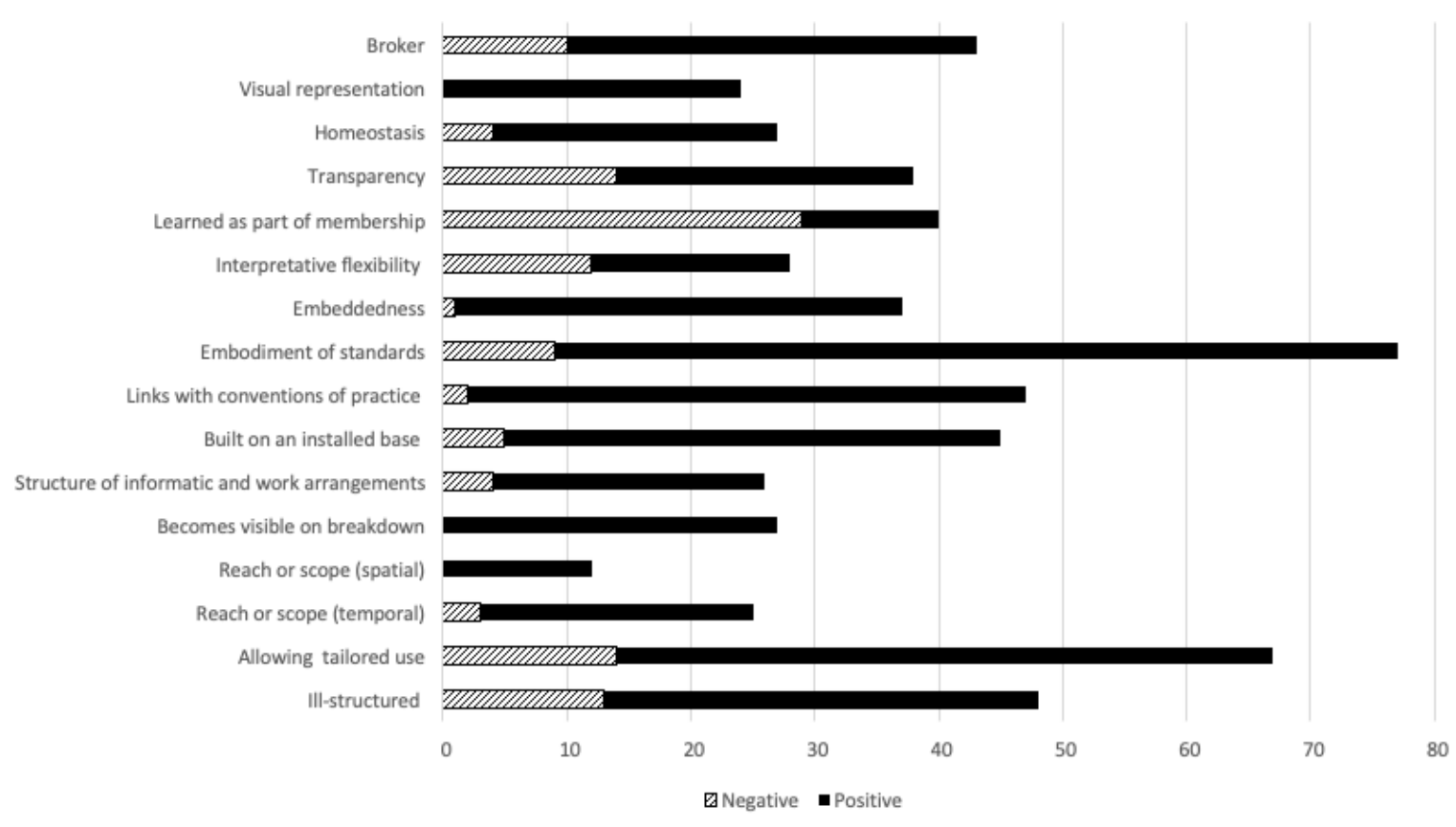

Figure 1: Bar chart showing the frequency of positive and negative BO feature citations

Three categories not included in Star's theory were identified: the first, homeostasis was included in the interview questions due to its recent appearance in BO literature (e.g. Datta and Acar, 2010); the second and third, brokers and visual representation were added after they emerged from interviewees' responses. Brokers and visual representation were identified in literature after Star's theory appeared (e.g. Wenger, 2000; 
Henderson, 1991). The validity of the data was improved by the variety of BOs researched across different disciplines. Data saturation was reached after only two interviews for both the internal and external teams and both groups mentioned the same BO features, reinforcing their relevance in this context.

\subsection{Star's effective features}

Although interpretative flexibility has been identified by the literature as a beneficial feature (e.g. Scoles, 2018; Koskinen and Mäkinen, 2009), there were concerns from participants that the interpretative aspects caused misinterpretation. The majority of respondents wanted a clearer picture of how the BOs they use work, as they were not trained to use them. Boundary infrastructure features relating to ill-structured while allowing tailored use were generally seen as positive. The participants appreciated the opportunity to access as much information as possible, but also "divide the areas so people can hone in on the bits that matter". Structure of informatic and work arrangements was frequently cited as positive (Figures 1 and 2) as by feeding into existing systems it could incorporate the lessons learned identified in KM literature (e.g. Luna-Reyes et al., 2018), which also made the BO easier to use and understand.

\subsection{Effective features not identified by Star}

The main features outside of Star's theory identified by participants were brokers, visual representation and homeostasis (Figure 3), primarily due to their ability to regulate quality and make BOs easier to use. Although few BOs examined were technologically advanced enough to have homeostasis, respondents saw this feature as a potential improvement to the BOs they were asked about. Star may have omitted this feature from her theory due to the first-order knowledge issues of participants in her study (1996, p.119) and because her focus was on BOs being used in the organisations under study.

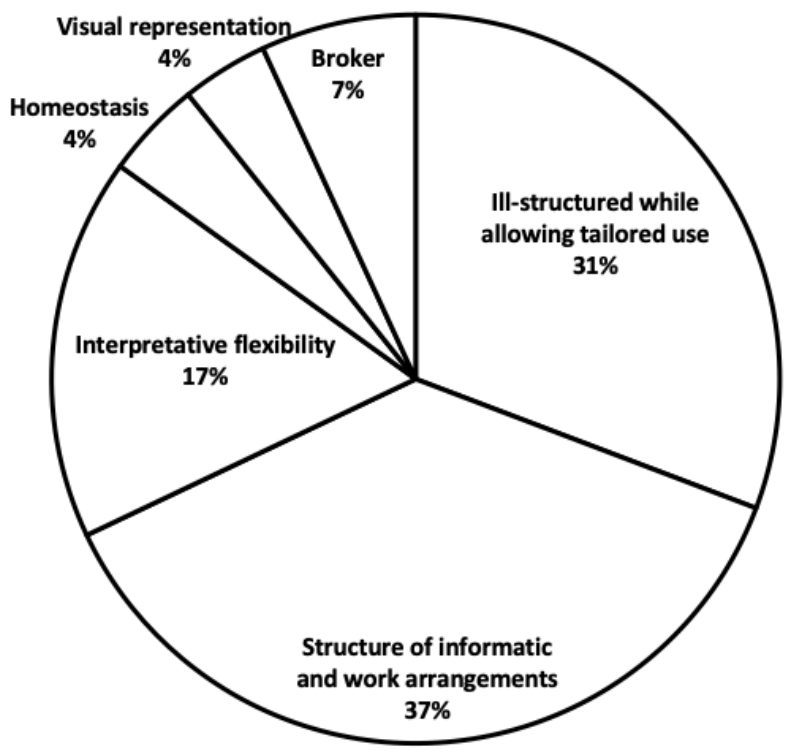

Figure 2: The frequency of each BO feature identified by the respondents

Brokers were cited frequently (Figure 1) by the participants as making BOs more effective due to their role as an updater, quality-controller and promoter of $\mathrm{BOs}$, by "getting the information together in a way that everybody can believe and use it". While Star did not include brokers in her theory, probably as they are not features of BOs, more recent studies with a focus on broker-BO interplay have emphasised their importance due to their understanding of local politics and ability to form informal networks (e.g. Harrison et al., 2018; Rosenkranz, Vranešić and Holten, 2014; Kimble, Grenier and Goglio-Primard, 2010).

Visual representation was identified by participants as "the best way of explaining things", which is consistent with other studies in environments where complex 3-D structures are built, such as construction and manufacturing (Henderson, 1991; Whyte et al., 2008; Dodgson, Gann and Salter, 2007). Star's theory may omit this feature as not all types of BO, like contracts and excel sheets, have it but the importance given to it by participants in this study indicates that it should be considered in future studies. 
To summarise, the results of this study show that Star's main features of BOs and boundary infrastructure are relevant to the construction industry and indicate which features may most effectively transfer knowledge between divisions, functions and organisations. While Star's theory remains relevant, the findings of the study suggest that it could be expanded to include homeostasis, visual representation and brokers so BOs can be more effective in practice.

\section{Conclusion}

This study has added to the body of knowledge on BOs by confirming that the most influential theory in the field is applicable to an industry where it had not yet been tested. As Star's theory has been a starting point for a large portion of studies into BOs over the past thirty years, reviewing its continued relevance is critical to the development of the field as a whole and this study has identified areas where further research into Star's theory is needed. The findings of this study support the idea that brokers can facilitate interplay between the tacit and explicit knowledge within an organisation.

Traditional construction project-based organisations are known for not only their complex, dispersed and temporary nature but also for rigid boundaries between processes, stakeholders and functions that hinder cooperation and knowledge transfer. Where there is little or no opportunity for face-to-face communication, BOs can be used to promote the sharing of knowledge in practice between diverse groups. The finding that all but one of these features were effective at transferring explicit knowledge suggests that organisations in this sector can improve performance by identifying and applying the most effective features to the BOs they use. BOs can be adapted to suit specific characteristics of project teams and some of the key themes cited by participants highlight the need to test new features of BOs to address $\mathrm{KM}$ and $\mathrm{OL}$ issues pertinent to a particular industry.

The findings of this research are not enough for general conclusions or statements, given that the study was based in one transport organisation that manages large-scale construction programmes and projects. The findings need further validation in other project-based industries. Further longitudinal research is needed on brokers' interactions with users through the lenses of ANT and CoPs to fully understand the impact of brokers on efficacy of BOs, and to understand whether homeostasis is an effective feature, and what its capabilities are in the frame of current and future technological developments.

\section{References}

Argote, L. (1999) Organizational Learning: Creating, Retaining, and Transferring Knowledge. Kluwer Academic Publishers, Boston.

Argyris, C. and Schön, D. A. (1978) Organisational Learning: a theory of action perspective. Addison-Wesley, Reading, Mass; London.

Azizi, N., Rowlands, B. and Haass, O. (2018) "Knowledge Sharing Within Organizations: Presenting a Conceptual Framework Based on the AKRI Approach", Paper read at 19 $9^{\text {th }}$ European Conference on Knowledge Management, Padua, Italy, July.

Biermann, S., and Martinus, K. (2016) “Boundary objects as tools for integrated land use-transport planning." in S Biermann, D Olaru and V Paul (eds), Planning Boomtown and Beyond. UWA Publishing, pp. 384-410.

Breengaard, L. C., Jørgensen, R. and Duncan, S. (2018) “Standardized Engineering: How Communities of Interest Facilitate Global Knowledge Sharing", Paper read at 19th European Conference on Knowledge Management, Padua, Italy, July.

Brown, J.S. and Duguid, P. (2001) "Knowledge and Organization: A Social-Practice Perspective", Organization Science, Vol 12, No. 2, pp. 198-213.

Cacciatori, E. (2008) "Memory objects in project environments: Storing, retrieving and adapting learning in project-based firms", Research Policy, Vol 37, No. 9, pp. 1591-1601.

Carlile, P.R. (2002) "A Pragmatic View of Knowledge and Boundaries: Boundary Objects in New Product Development", Organization Science, Vol 13, No. 4, pp. 442-455.

Cash, D.W., Clark, W.C., Alcock, F., Dickson, N.M., Eckley, N., Guston, D.H., Jäger, J. and Mitchell, R.B. (2003) "Knowledge systems for sustainable development", Proceedings of the National Academy of Sciences of the United States of America, Vol 100, No. 14, pp. 8086-8091.

Datta, P. and Acar, W. (2010) "Software and human agents in Knowledge Codification", Knowledge Management Research and Practice, Vol 8, No. 1, pp. 45-60.

Dodgson, M., Gann, D.M. and Salter, A. (2007) "'In Case of Fire, Please Use the Elevator': Simulation Technology and Organization in Fire Engineering", Organization Science, Vol 18, No. 5, pp.849-864.

Eriksson, P. (2010) "Improving construction supply chain collaboration and performance: a lean construction pilot project", Supply Chain Management: An International Journal, Vol 15, No. 5, pp.394-403.

Gourlay, S. (2007) "An Activity Centered Framework for Knowledge Management" in (eds) Mclnerney, C. R. and Day, R. E., Rethinking Knowledge Management: from knowledge objects to knowledge processes, pp.21-64. New York, Springer. 


\section{Rosanna Butters and Meri Duryan}

Gummesson, E. (2000) Qualitative methods in management research. Thousand Oaks, CA. Sage Publications. Henderson, K. (1991) "Flexible Sketches and Inflexible Data Bases: Visual Communication, Conscription Devices, and Boundary Objects in Design Engineering." Science, Technology, and Human Values, Vol 16, No. 4, pp. 448-473.

Harrison, D., Hoholm, T., Prenkert, F. and Olsen P. I. (2018) "Boundary objects in network interactions", Industrial Marketing Management, Vol 74, pp.187-194.

Huvila, I., Anderson, D. T., Jansen, E. H., Mckenzie, P., Worrall, A. (2017) "Boundary Objects in Information Science", Journal of the Association for Information Science and Technology, Vol 68, No. 8, pp.1807-1822.

Hustad, E. (2007) "Managing Structural Diversity: the Case of Boundary Spanning Networks", Electronic Journal of Knowledge Management, Vol 5, No. 4, pp.399-410.

Luna-Reyes, L. F., Black, L. J., Ran, W., Lines Anderson, D., Jarmen, H., Richardson, G. P. and Andersen, D. F. (2018) "Modeling and Simulation as Boundary Objects to Facilitate Interdisciplinary Research," Systems Research and Behavioral Science, [online], Wiley Online Library, https://onlinelibrary.wiley.com/doi/abs/10.1002/sres.2564.

Kanwal, S., Baptista Nunes, M., Arif, M. and Hui, C. (2018) "A Review and Classification of Boundary Objects use in Knowledge Management Practices", Paper read at $15^{\text {th }}$ International Conference on Intellectual Capital, Knowledge Management and Organisational Learning, University of Western Cape, South Africa, November.

Kimble, C., Grenier C., and Goglio-Primard, K. (2010) "Innovation and knowledge sharing across professional boundaries: Political interplay between boundary objects and brokers", International Journal of Information Management, Vol 30, pp. 437-444.

Koskinen, K.U. and Mäkinen, S. (2009) "Role of boundary objects in negotiations of project contracts", International Journal of Project Management, Vol 27, No. 1, pp. 31-38.

Kotnour, T. (2000) "Organizational learning practices in the project management environment", International Journal of Quality and Reliability Management, Vol 17, No. 4/5, pp. 393-406.

Lipshitz, R., Popper, M. and Friedman, V.J. (2002) "A multifacet model of organizational learning", The Journal Of Applied Behavioral Science, Vol 38, No. 1, pp. 78-98.

Morris, P. W. G. and Loch, I. (2006) "Project-based learning: learning issues in projects", Bartlett Research, London.

MacEachren, A.M. (2001) "Cartography and GIS: Extending collaborative tools to support virtual teams", Progress in Human Geography, Vol 25, No. 3, pp.431-444.

Polanyi, M. (1967) The Tacit Dimension. Doubleday, New York.

Rosenkranz, C., Vranešić, H., Holten, R. (2014) "Boundary Interactions and Motors of Change in Requirements Elicitation: A Dynamic Perspective on Knowledge Sharing", Journal of the Association for Information Systems, Vol 15, No. 6, pp. 306-345.

Sajtos, L, Kleinaltenkamp, M., Harrison, J. (2018) "Boundary objects for institutional work across service ecosystems", Journal of Service Management, Vol 29, No. 4, pp. 615-640.

Scoles, J. (2018) "Researching 'messy objects': how can boundary objects strengthen the analytical pursuit of an actornetwork theory study?", Studies in Continuing Education, Special Issue, pp.1-17.

Smyth, H. J. (2006) "Competition" in eds. D. Lowe and R. Leiringer, Commercial Management of Projects: Defining the discipline, Blackwell, Oxford.

Star, S.L. (1989) "The Structure of III-Structured Solutions: Boundary Objects and Heterogeneous Distributed Problem Solving", In Distributed Artificial Intelligence, pp. 37-54.

Star, S.L. (2010) "This is not a boundary object: Reflections on the origin of a concept", Science Technology and Human Values, Vol 35, No. 5, pp.601-617.

Star, S.L. and Griesemer, J.R. (1989) “Institutional Ecology, 'Translations' and Boundary Objects: Amateurs and Professionals in Berkeley's Museum of Vertebrate Zoology, 1907-39", Social Studies of Science, Vol 19, No. 3, pp. 387-420.

Star, S.L. and Ruhleder, K. (1996) "Steps Toward an Ecology of Infrastructure: Design and Access for Large Information Spaces", Information Systems Research, Vol 7, No. 1, pp. 111-134.

Szulanski, G. (2000) "The Process of Knowledge Transfer: A Diachronic Analysis of Stickiness", Organizational Behavior and Human Decision Processes, Vol 82, No. 1, pp. 9-27.

Thomas, R., Sargent, L., and Hardy, C. (2008) "Power and participation in the production of boundary objects", Working Paper Series, Cardiff Business School.

Thompson, E. (2016) "An Actor-Network Theory of Boundary Objects: Construction and Disappearance", British Academy of Management Conference 2016, Newcastle.

Wenger, E. (2000) "Communities of Practice and Social Learning Systems", Organization, Vol 7, No. 2, pp.225-246.

Wenger, E. (2010) "Communities of Practice and Social Learning Systems: the Career of a Concept" in Blackmoor, C. (ed) Social Learning Systems and Communities of Practice, pp. 179-198. Springer; London.

Whyte, J. Ewenstein, B., Hales, M. and Tidd, J. (2008) "Visualizing Knowledge in Project-Based Work", Long Range Planning, Vol 41, No. 1, pp. 74-92.

Williams, T. (2008) "How do organizations learn lessons from projects - and do they?", IEEE Transactions on Engineering Management, Vol 55, No. 2, pp. 248-266.

Yakura, E.K. (2002) “Charting time: Timelines as temporal boundary objects", Academy of Management Journal, Vol 45, No. 5, pp. 956-970.

Yin, R. (2018) Case Study Research and Applications: Design and Methods, $6^{\text {th }}$ edition, Thousand Oaks, CA; Sage Publications. 